\title{
Editorial
}

Article DOI:

https://doi.org/10.35293/srsa.v42i2.71

\section{Strategic Shifts and Twists, Africa and Southern Africa}

There is no question that there are several shifts that Southern Africa and Africa is experiencing as a result of a combination of factors including the geopolitical rise of the East in world affairs in competition with the West. The competition manifests itself also in the growing role of China and Russia in African affairs. But whether the shifts will lead to deeper cooperation and more meaning full partnerships between these global powers and Africa depends on a number of factors including the strategic foresight on the part of Africa or African countries. In this regard, how countries like South Africa and Nigeria as major African countries seize opportunities will tell us whether they have strategic capabilities to take advantage of Africa being thrust into the middle of shifts and twists in world affairs and power reconfiguration. Articles in this edition contribute in their different ways to this discussion.

Neethling casts a critical eye on Russia's growing engagements in Africa, helping to clarify how these are shaped by the prominence of strategic geoeconomic interests in Moscow, especially energy power considerations. Economic interests loom large also in the paper by Jurenczyk investigating China's approach to engagement with Africa using the case of Angola to find a holistic characterisation of a Chinese model of economic co-operation.

Matambo focuses on how China's strategic partnership with South Africa is shaped by history, identity and interests, showing that some trade-offs that this entails present a risk to South Africa's values and strategic posture. Maphaka's article goes a little deeper on this relationship by seeking to explain the strategic calculus on the part of South Africa during a period when there were apparent attempts to deepen engagement with Beijing.

The analyses by Makgetlaneng, Gumede and Khambule focus on South Africa per se. Makgetlaneng discusses how South Africa positions itself to contribute to global, continental and regional transformation in the hope that this will help bring about a new Southern Africa, Africa and the world. This is about creating conditions for the achievement of enlightened national interests where this means going beyond narrow national interests towards a focus on the country's shared interests with its neighbours. 
Gumede turns to domestic conditions relating to the unfinished business of the making of the South African nation, which he contends require the achievement of reconciliation and inclusive development at the same time. He however shows that this achievement remains elusive, thus deferring the dreams of liberation for the majority of the population. Khambule analyses the role and contribution of subnational institutions in strengthening South Africa's emerging democratic developmental state through developmental local government. It thus make a case for building the new state a new from below.

Vhumbunu turns our attention to the regional challenge of human trafficking, demonstrating that the problem is growing, yet the southern African region has a raft of policies to guide an effective fight against the crime. The article identifies shortcomings and makes recommendations towards stronger regional responses.

The work of Afolabi is a timely intervention in the debate about electronic electoral systems as a way in which new technologies might help deepen democratic consolidation and reduce electoral fraud. Using Nigeria and Zimbabwe as case studies, the article demonstrates divergent outcomes between the two cases in the assessment of electronic voting as a measure to reduce electoral fraud and it draws out lessons for a more effective implementation of e-voting systems.

The edition thus helps us engage in strategic reflections about a range of different but connected issues related to shifts and twists happening in Africa.

I would like to appreciate the authors and reviewers for their hard work as well as editorial assistants for their contribution to this edition. The editorial group, especially Professors Benyera and Shai, are a source of ideas, guidance and insights.

Siphamandla Zondi

Editor-in-Chief

April 2020 
